AL-IQTISHOD: Jurnal Pemikiran dan Penelitian Ekonomi Islam

E-ISSN: 2407-6600 P-ISSN: 2745-85I2

Volume I0 Issue I Januari 2022 | Page: II3-I30

DOI: https://doi.org/I0.37812/aliqtishod

\title{
STRATEGI MENINGKATKAN FUNDING DIMASA PANDEMI PADA BANK SYARIAH INDONESIA KCP SUMBERREJO BOJONEGORO
}

\author{
Intan Ayu \\ Sekolah Tinggi Agama Islam (STAI) Attanwir Bojonegoro \\ Intan22diamond@,gmail.com \\ Putri Wulandari \\ Sekolah Tinggi Agama Islam (STAI) Attanwir Bojonegoro \\ putrindari226@gmail.com \\ Sutiya Lestari \\ Sekolah Tinggi Agama Islam (STAI) Attanwir Bojonegoro \\ sutiyalestari@,gmail.com
}

\begin{abstract}
During the pandemic, almost all economic sectors were affected and there were many declines, one of which was Islamic banks. As a fund-raising institution, when the economy experiences a decline, their funding will also experience a decline. This research was conducted at the Indonesian Islamic Bank KCP Sumberrejo Bojonegoro. The purpose of this study was to determine the strategy to increase funding carried out by Indonesian Islamic banks during the pandemic. This research is a qualitative descriptive study with data collection methods in the form of interviews and documentation. The results of this study are the Indonesian Islamic bank KCP Sumberrejo Bojonegoro using product strategies, promotions, advertising, minimizing opening of funds and visits to increase funding during the pandemic, and the obstacles experienced are many customers who seek funds and competition between Islamic financial institutions.
\end{abstract}

Keywords: islamic banks, funding, strategy.

Abstrak: Saat pandemi hampir semua sektor perkenomian terkena dampak dan banyak mengalami penurunan, salah satunya adalah bank syariah. Sebagai lembaga penghimpun dana, ketika perekonomian mengalami penurunan maka funding mereka pun juga akan mengalami penurunan. Penelitian ini dilakukan di bank syariah Indonesia kcp sumberrejo bojonegoro. Tujuan penelitian ini adalah untuk mengetahui strategi meningkatkan funding yang dilakukan bank syariah Indonesia selama masa pandemi. Penelitian ini merupakan penelitian deskriptif kualitatif dengan metode pengumpulan data berupa wawancara dan dokumentasi. Hasil dari penelitian ini adalah bank syariah Indonesia kcp sumberrejo bojonegoro menggunakan strategi produk, promosi, iklan, peminimalisiran pencairan dana dan kunjungan untuk meningkatkan funding di masa pandemi, dan kendala yang di alami adalah banyaknya nasabah yang melakukan pencairan dana dan persaingan antar lembaga keuangan syariah.

Kata kunci: bank syariah, funding, strategi. 



\section{A. Pendahuluan}

Pada era sekarang Bank Syariah di Indonesia mengalami perkembangan yang cukup pesat, karena masyarakat Indonesia yang mayoritas adalah muslim sehingga Bank Syariah memiliki peranan yang besar dalam membangun perekonomian. Undang - Undang Perbankan Syariah mendorong peningkatan jumlah BUS dari sebesar lima BUS menjadi sebelas BUS dalam waktu kurang dua tahun (2009-2010). Sejak dikembangkannya sistem perbankan syariah di Indonesia, terjadi banyak kemajuan dalam dua dekade. Mulai dari aspek infrastruktur penunjang, regulasi dan sistem pengawasan, kesadaran serta literasi masyarakat terhadap layanan jasa keuangan syariah. Pada tahun 2019 ada sekitar I97 bank syariah yang terdiri dari I4 Bank Umum Syariah (BUS), 20 Unit Usaha Syariah (UUS), dan I63 Bank Pembiayaan Rakyat Syariah (BPRS) di Indonesia.

Hadirnya bank syariah raksasa di Indonesia membuat perkembangan bank syariah semakin meningkat, yaitu Bank Syariah Indonesia (BSI) yang lahir dari gabungan tiga bank ternama, antara lain Bank Mandiri Syariah, Bank BNI Syariah, dan Bank BRI Syariah. Kehadiran Bank syariah Indonesia (BSI) ini menjadi peristiwa baru bagi bangsa ini. Dengan penggabungan tiga bank plat merah tersebut, Indonesia ditargetkan menjadi pusat ekonomi dan keuangan syariah di dunia. Menurut data yang didapatkan, Bank Syariah Indonesia kini menjelma menjadi raksasa baru bank syariah dunia, dan berada di posisi 2I terbesar sedunia dari sisi aset (per Juni 202I). Dengan aset setara US\$ 17,3 miliar, BSI mengekor Public Islamic Bank asal Malaysia yang asetnya sebesar US\$ I7,8 miliar.

Namun pada tahun 2019 sampai sekarang dunia tengah mengalami sebuah pandemik yang memberikan pengaruh terhadap semua sektor termasuk sektor perekonomian. Pandemik menjadi tantangan baru bagi perbankan syariah. Tapi perbankan syariah merupakan perbankan yang terkenal dengan ketahanannya terhadap krisis ekonomi. Hal ini bisa dilihat pada saat krisis tahun I998, perbankan syariah 
menjadi satu-satunya bank yang mampu bertahan bahkan berkembang. Perbandingan kekuatan antara bank syariah dan bank komvensional dalam menghadapi krisis pandemi dapat dilihat dari beberapa sudut pandang. Dalam hal penyaluran kredit (pembiayaan), bank syariah maupun bank konvensional sama-sama mengalami perlambatan penyaluran kredit (pembiayaan). Sama halnya dengan penyaluran kredit, adanya POJK NO.II/POJK.03/2020 dapat membantu perbankan syariah maupun konvensional dalam cadangan penghapusan aktiva produktif. Dan hal yamg terakhir, hal yang berbeda dari kedua bank tersebut adalah bank syariah menggunakan sistem bagi hasil neraca bank syariah akan elastis karena besarnya biaya untuk pembayaran bagi hasil akan ikut menurun sejalan dengan penurunan pendapatan bank syariah. Sedangkan bank konvensional menggunakan sistem bunga. Ketika pendapatan bunga kredit mengalami penurunan hal ini tidak diikuti dengan penurunan biaya bunga untuk deposan. Sehingga ini menjadi permasalahan serius dari bank konvensional.

Banyak keunggulan dari Bank syariah akan tetapi, masih memiliki catatan negative dalam menghadapi pandemi. Diantaranya yaitu penurunan margin dengan net operating margin turun I,55\% dan beban operasional pada pendapatan operasional sebesar 83,63\%. Pangsa pasar juga relative rendah dimana masih 0,93\% untuk indeks literasi dan 9,I\% untuk inklusi syariah. Sementara itu, secara nasional, indeks literasinya sudah 38,03\% dan inklusi keuangan 76,19\%. .

Beberapa permasalahan yang disampaikan diatas, penulis merasa tertarik untuk melakukan penelitian apakah pandemi ini memberikan pengaruh yang besar bagi Bank Syariah Indonesia. Dan bagaimana cara Bank Syariah Indonesia bertahan dan meningkatkan fundingnya dimasa pandemi seperti sekarang ini. Sehingga penulis memutuskan untuk membuat judul "STRATEGI MENINGKATKAN FUNDING DI MASA PANDEMI PADA BANK SYARIAH INDONESIA KCP SUMBERREJO BOJONEGORO” 


\section{B. Kajian Pustaka}

Sutiya Lestari

\section{Bank Syariah}

Bank Islam (selanjutnya disebut bank syariah) adalah bank yang tidak bergantung pada kepentingan usahanya. Bank syariah atau bank bebas bunga adalah lembaga keuangan/perbankan yang bisnis dan produknya berpedoman pada Al-Qur'an dan hadits Nabi SAW. Dengan kata lain, bank syariah adalah lembaga keuangan yang kegiatan utamanya adalah menyediakan pembiayaan dan jasa-jasa lain lalulintas pembiayaan dan peredaran uang, yang pengoperasiannya sesuai dengan prinsip-prinsip hukum Islam. ${ }^{\mathrm{I}}$

Tujuan dari perbankan syariah adalah menunjang pelaksaan pembangunan nasional dalam rangka meningkatkan keadilan, kebersamaan, dan pemerataan kesejahteraan rakyat. ${ }^{2}$ Sedangkan fungsi awal dari Bank Syariah adalah:

a. Menghimpun dana dari masyarakat dalam bentuk titipan atau tabungan dan investasi

b. Menyalurkan dana kepada masyarakat yang membutuhkan dana dari Bank dalam bentuk pembiayaan atau kredit

c. Memberikan pelayanan dalam bentuk jasa perbankan syariah.

\section{Penghimpunan Dana (funding)}

Funding disebut juga dengan penghimpunan dana. Dana adalah uang tunai atau aktiva lainnya yang segera dapat diuangkan dan yang tersedia atau disisihkan untuk maksud tertentu. Semakin besar dana yang dapat dihimpun oleh masyarakat, maka akan semakin besar kemungkinan dapat memberikan kredit dan berarti semakin besar lembaga memperoleh penghasilan, sebaliknya semakin kecil dana

\footnotetext{
I Zulkifli Rusby, Manajemen Perbankan Syariah, (Pekanbaru: Pusat Kajian Pendidikan Islam FAI UIR, 2017) I.

2 Andrianto \& M. Anang Firmansyah, Manajemen Bank Syariah_(Surabaya: CV. Penerbit Qiara Media, 2019), 27.
}

Volume. I0/No. I/Januari 2022 Al-Iqtishod | I I5 
yang dihimpun dari masyarakat, maka semakin kecil pula kredit yang diberikan, sehingga semakin kecil pula penghasilan yang diperoleh oleh lembaga tersebut. ${ }^{3}$

Penghimpunan dana merupakan suatu kegiatan usaha dari lembaga keuangan dalam menarik dan mengumpulkan dari beberapa dana dari masyarakat dan menampungnya dalam bentuk simpanan, giro, tabungan, deposito, atau surat berharga lainnya. ${ }^{4}$

Landasan hukum penghimpunan dana perbankan syariah terdiri dari AlQur'an, Al-Hadis:

a. Al-Qur'an

I) QS. An-Nisa ayat 29: "Hai orang-orang yang beriman, janganlah kamu memakan harta sesamamu dengan jalan yang curang. Kecuali dengan cara perdagangan yang berlaku dengan sukarela di antara kamu."

2) Q.S. Ali-Imran ayat I30: "Hai orang-orang yang beriman, janganlah kamu memakan riba dengan berlipat ganda dan bertawakallah kamu kepada Allah supaya kamu mendapat keberuntungan."

b. Al-Hadis

I) HR. Abu Daud, yang dishahihkan oleh al-Hakim, dari Abu Hurairah: "Sesungguhnya Allah SWT berfirman: "Aku pihak ketiga dari dua orang yang bersyarikat selama salah satunya tidak menghianati temannya."

2) HR. Tirmidzi dari 'Amr bin 'Auf: "Kaum muslimin terikat dengan syaratsyarat yang mereka buat kecuali syarat yang mengharamkan yang halal atau menghalalkan yang haram."

Manfaat funding atau lpenghimpunan dana antara lain: ${ }^{5}$

a. Bagi bank

\footnotetext{
${ }^{3}$ Frianto Pandia, Manajemen Dana dan Kesehatan Bank, (Jakarta: Rineka Cipta, 2012)I.

${ }^{4}$ Fitri Nurhatati dan Ika Saniyati Rahmaniyah, Koperasi Syariah, (Surakarta: PT. Era Intermedia, 2008)I6.

${ }^{5}$ Frianto Pandia, Manajemen Dana dan Kesehatan Bank, (Jakarta: Rineka Cipta, 20I2) 10.
} 
Sebagai tambahan modal untuk pemberian pinjaman atau pembiayaan ataupun kredit untuk masyarakat yang membutuhkan. Dan dari pinjaman tau pembiayaan tersebut bank akan memperoleh bagi hasil.

b. Pemilik uang

Dengan adanya penghimpunan dana, uang investor menjadi lebih produktif dan menghasilkan keuntungan.

c. Bagi pemerintah

Dengan adanya penghimpunan dana maka dapat mengurangi volume uang yang beredar dimasyarakat. Dan merupakan salah satu usaha pengendalian inflasi.

Tujuan funding atau lpenghimpunan dana bank adalah: ${ }^{6}$
a. Sebagai dana operasional bank
b. Salah satu cara Pemerintah dalam Melaksanakan Kebijaksanaan Moneter
c. Produktivitas dana.

\section{Produk Penghimpunan Dana (funding)}

\section{a. Giro}

Simpanan Giro adalah simpanan bank yang penarikannya dapat dilakukan dengan cek atau giro. Semua pemegang rekening giro menerima bunga, yang dikenal sebagai jasa giro. Jumlah jasa yang diterima tergantung dari bank tersebut. Rekening giro banyak digunakan oleh pengusaha perorangan maupun perusahaan. Bagi bank, jasa giro merupakan pilihan yang lebih murah karena dana yang diberikan kepada nasabahnya relatif lebih rendah dibandingkan dengan suku bunga simpanan lainnya. ${ }^{7}$

\footnotetext{
${ }^{6}$ Ibid., II.

${ }^{7}$ Muhammad Syafi'i Antonio, Bank Syariah Dari Teori Ke Praktik(Depok: Gema Insani, 200I), I85.
} 


\section{b. Tabungan}

Tabungan adalah simpanan yang hanya dapat ditarik dengan syaratsyarat tertentu yang disepakati dan tidak dapat ditarik dengan cek, setoran di tempat, latau cara pembayaran lain yang dipersamakan dengan itu. Nasabah yang ingin melakukan setoran dapat langsung datang ke bank dengan membawa cek, slip pembayaran, atau ATM. ${ }^{8}$

Dalam transaksi mudharabah, nasabah bertindak sebagai pemilik dana (shahibul mal) dan bank bertindak sebagai pengelola dana (mudharib). Dana yang disimpan di bank sebagai modal dari tabungan Mudarabah harus disajikan berbentuk tunai dan bukan merupakan off setting dari piutang nasabah. Nasabah wajib menjaga minimal saldo yang ditetapkan oleh bank dan tidak dapat ditarik kecuali rekening ditutup. Bagi hasil dinyatakan dalam bentuk nisbah dan harus dituangkan dalam kontrak pembukaan rekening.

Bagi hasil dalam mudharabah dapat dilakukan dengan dua cara yaitu pertama: bagi laba (profit sharing) atau bagi pendapatan (revenue sharing). Metode kedua bagi laba (profit sharing) dihitung dari total pendapatan dikurangi semua biaya operasional. Metode bagi pendapatan (revenue sharing) dihitung dari total pendapatan mudharabah yang diterima dari bank. ${ }^{9}$

\section{c. Deposito}

Deposito adalah simpanan yang memiliki jangka waktu tertentu (jatuh tempo). Penarikannya dilakukan sesuai jangka waktu tersebut berdasarkan lkesepakatan antara nasabah dan bank. ${ }^{10}$ Dalam praktik pembiayaan, bank syariah memiliki prinsip yang berbeda dengan prinsip dari perbankan konvensional. Dalam transaksi deposito mudharabah, nasabah bertindak sebagai pemilik dana (shahibul mal) dan bank bertindak sebagai pengelola dana (mudharib). Bagi hasil dinyatakan dalam bentuk nisbah dan harus dituangkan

\footnotetext{
${ }^{8}$ Abdul Ghafur Anshari, Perbankan Syariah di Indonesia, (Jogjakarta: UGM Press, 2007) 87.

${ }^{9}$ Muhammad, Audit dan Pengawasan (Jogjakarta: UII Press, 2018) 43.

${ }^{\text {I0 }}$ Muhammad, Manajemen Dana Bank Syariah (Jakarta: Rajagrafindo Persada, 20I4) 38.
} 
Intan Ayu, Putri Wulandari,

Sutiya Lestari

dalam kontrak pembukaan rekening. Bagi hasil dalam mudharabah dapat dilakukan dengan dua cara yaitu bagi laba (profit sharing) atau bagi pendapatan (revenue sharing) ${ }^{11}$. Metode bagi laba (profit sharing) dihitung dari total pendapatan dikurangi semua biaya operasional. Metode bagi pendapatan (revenue sharing) dihitung dari total pendapatan mudharabah yang diterima dari bank.

\section{Strategi Meningkatkan Funding}

Strategi merupakan penentuan kerangka dari aktivitas bisnis perusahaan dan lmemberikan pedoman untuk mengkoordinasikan aktivitas sehingga perusahaan dapat menyesuaikan dan mempengaruhi lingkungan yang selalu berubah. ${ }^{12}$ Sedangkan peningkatan funding adalah upaya untuk meningkatkan simpanan yang telah ada untuk mencapai target penghimpunan dana.

Untuk lmeningkatkan jumlah nasabah guna meningkatkan jumlah funding, lembaga keuangan menggunakan beberapa strategi.Strategi pemasaran yaitu suatu upaya untuk memasarkan dan mengenalkan produk ataupun jasa kepada masyarakat. Dan dapat dikatakan strategi pemasaran adalah serangkaian tujuan dan sasaran, serta kebijakan dan aturan yang memberi arah kepada usaha-usaha pemasaran perusahaan dari waktu ke waktu pada masing-masing tingkatan dan acuan serta lokasinya, terutama sebagai tanggapan perusahan dalam menghadapi lingkungan dan keadaan pesaing yang selau dinamis. ${ }^{13}$

Bauran pemasaran yaitu kesatuan alat pemasaran taktis, yang terkendali yang dipadukan perusahaan untuk menghasilkan respons yang diinginkannya

11 Sutono STAI Al-Azhar Menganti Gresik, "IMPLIKASI AKAD MUSYARAKAH MUTANAQISAH PERBANKAN SYARI'AH," Al Iqtishod: Jurnal Pemikiran Dan Penelitian Ekonomi Islam 8, no. 2 (December 28, 2020): 1-19, https://doi.org/10.37812/ALIQTISHOD.V8I2.152.

${ }^{12}$ Mudrajad Kuncoro, Strategi Bagaimana Meraih Keunggulan Kompetitif, (Jakarta : Erlangga, 2005), I2 13 Ali Muhayatsyah et al., "PENGARUH KRISIS EKONOMI 2008 DAN FAKTOR FUNDAMENTAL TERHADAP PENYALURAN PEMBIAYAAN BANK SYARIAH DI INDONESIA," Jurnal Ekonomi Syariah, Akuntansi Dan Perbankan (JESKaPe) 4, no. 1 (July 27, 2020): 125-124, https://doi.org/10.52490/JESKAPE.V4I1.772.

Volume. I0/No. I/Januari 2022 Al-Iqtishod | I I9 
dipasar sasaran. Bauran pemasaran juga dapat diartikan sebagai strategi inovasi yang dilakukan oleh perusahaan dalam bidang pemasaran. 1Dalam dunia perbankan penggunaan bauran pemasaran ini dilakukan sesuai dengan kebutuhan bank. Menurt Phillip Kotler bauran pemasaran menyebutkan ada $4 \mathrm{P}$ yaitu: ${ }^{14}$

a. Product (produk)

Produk adalah suatu barang dengan label atau merek dagang yang disediakan oleh produk tersebut, baik dijual kepada konsumen maupun tidak. Untuk menarik konsumen agar produk yang ditawarkan memenuhi tujuannya, maka diperlukan strategi pengembangan produk di bawah ini:

I) Penentuan logo dan moto

2) Menciptakan merk

3) Menciptakan kemasan

4) Keputusan label

b. price (harga)

Price ialah ljumlah yang harus dibayar konsumen untuk mendapatkan produk yang diinginkan. Atau, harga dapat diartikan sebagai cerminan nilai.

c. place (lokasi)

Berbagai lkegiatan perusahaan membuat produk yang diproduksi/dijual tersedia di pasar sasaran dengan harga yang terjangkau. Lokasi termasuk saluran, cakupan, bermacam-macam, lokasi, inventaris, dan pengiriman.

d. promotion (promosi)

Suatu lkegiatan yang dilakukan oleh perusahaan untuk menjelaskan manfaat suatu produka agar konsumen tertarik untuk membeli produk tersebut.

e. Kemudian marketing mix syariah adalah disiplin sebuah disiplin bisnis strategis yang mengarahkan prosespenciptaan,penawaran, dan perubahan

${ }^{14}$ Eko Mardiyanto, Stai Al-Azhar, and Menganti Gresik, "Implementasi Marketing Mix Dalam Pemasaran Perbankan Syariah," Al Iqtishod: Jurnal Pemikiran Dan Penelitian Ekonomi Islam 9, no. 1 (March 30, 2021): 93-103, https://doi.org/10.37812/ALIQTISHOD.V9I1.227. 
Intan Ayu, Putri Wulandari, Sutiya Lestari value dari suatu inisiator kepada stakeoldersnya yang dalam keseluruhanprosesnya sesuai dengan akad dan prinsip-prinsip muamalah (bisnis) dala Islam. Artinya dalam marketing mix syariah seluru proses, baik proses penciptaan, proses penawaran, maupun proses perubahan nilai tidak boleh ada hal-hal yang berentangan dengan akad dan prinsip -prinsip muamalah yang Islami. ${ }^{15}$

\section{Metode Penelitian}

Jenis penelitian yang digunakan dalam penelitian ini adalah penelitian kualitatif yang cenderung menggunakan analisis. Dalam penelitian ini proses dan makna lebih banyak ditonjolkan dengan menggunakan landasan teori sebagai panduan fokus pada penelitian sesuai dengan fakta di lapangan. Berdasarkan penjelasan diatas dapat diketahui bahwa penelitian ini bersifat deskriptif kualitatif karena berupa kata-kata yang menjelaskan keadaan suatu hal. Data yang diperoleh dari naskah wawancara, dokumentasi, rekaman, dokumen resmi dan lain-lain.

Penelitian yang dilakukan oleh penulis bertempat di Bank Syariah Indonesia (BSI) yang berlokasi di Jl. Raya Sumberrejo No. 3I0, Sumberrejo, Bojonegoro, Jawa Timur. Dalam penelitian ini ada dua sumber data yang digunakan oleh penulis yaitu data primer dan data sekunder. Data Primer adalah data yang diperoleh secara langsung melalui wawancara terhadap informan. Data Sekunder adalah sumber data yang diperoleh untuk memperoleh data yang dibutuhkan, biasanya berasal dari kepustakaan. Dalam penelitian ini sumber data sekunder didapatkan dari buku-buku perbankan syariah.

Beberapa teknik pengumpulan data yang digunakan oleh penulis yaitu wawancara dan dokumentasi. Wawancara adalah tanya jawab dengan seseorang yang diperlukan untuk dimintai keterangan atau pendapatnya mengenai suatu hal. ${ }^{16}$ Data yang penulis harapkan dari metode wawancara tersebut adalah data tentang startegi

${ }^{15}$ Kertajaya dan Sula, Syariah Marketing (Bandung : Mizan Pustaka, 2006), 22.

${ }^{16} \mathrm{Kbbi}$, Wawancara dalam http:kbbi.web.id/wawancara.html/ diakses 19 Desember $202 \mathrm{I}$.

Volume. IO/No. I/Januari 2022 Al-Iqtishod | I2I 
Strategi Meningkatkan Funding......

meningkatkan funding dimasa pandemic pada BSI kcp Sumberrejo Bojonegoro. Metode wawacara yang digunakan adalah wawancara terstruktur karena pertanyaan sudah disusun sebelum wawancara dilakukan. Wawancara pada penelitian ini dilakukan pada General Support Staff Bagus B. FTS Devi 1. RSE dan SFE M. Mukhlis Auli A. Dokumentasi adalah mencari data mengenai variabel berupa catatan, transkrip, buku, surat kabar, majalah dan lain-lain.

Teknik analisi data penelitian ini menggunakan analisis data kualitatif model Miles dan Huberman,dimana analisis data melalui tiga kegiatan, yaitu reduksi data, model data (data display) dan penarikan atau verivikasi kesimpulan. ${ }^{17}$ Reduksi data merupakan langkah awal dalam analisis data berupa catatan dari hasil analysis lapangan, dimana data diperoleh melalui observasi, wawancara dan dokumentasi dengan mengambil data pokok dan membuang hal yang tidak perlukan dalam penelitian. Setelah itu tahapan model data (data display), dimana peneliti menyajikan data yang diperoleh dengan singkat dan jelas untuk memudahkan pemahaman terhadap setiap masalah dalam penelitian ini. Langkah terakhir adalah penarikan atau verifikasi kesimpulan, dimana peneliti mengintrepretasikan hasil penelitian setelah dilakukan reduksi data dan data display. ${ }^{18}$

\section{Hasil dan Pembahasan}

\section{Profil Bank Syariah Indonesia Kcp Sumberrejo Bojonegoro}

Indonesia berpotensi menjadi yang utama dalam industri keuangan syariah. Peningkatan kesadaran masyarakat terhadap bahan halal dan dukungan kuat dari para pemangku kepentingan menjadi faktor penting dalam mengembangkan ekosistem industri halal Indonesia, termasuk bank syariah.

\footnotetext{
${ }^{17}$ Haris Herdiansyah, Wawancara, Observasi dan Focus Groups sebagai Instrumen Penggalian data kualitatif(Jakarta: Rajawal Pers, 2013), I29-I34.

18 Ahmad Taufiqur Rahman et al., "Analisis Partisipasi Masyarakat Nahdlatul Ulama Dalam Meingkatkan Pendapatan Dana (Funding) Lazisnu Kota Sumenep," Ulumuna: Jurnal Studi Keislaman 7, no. 2 (December 12, 2021): 243-60, http://ejournal.kopertais4.or.id/madura/index.php/ulumuna/article/view/5258.
} 
Bank Syariah memainkan peran penting sebagai perantara untuk semua kegiatan ekonomi ldalam ekosistem industri Halal. Adanya industri perbankan syariah di Indonesia sendiri telah tumbuh secara signifikan sepanjang tiga dekade terakhir. Inovasi produk, peningkatan layanan, dan pengembangan jaringan menunjukkan tren positif dari tahun ke tahun. Bahkan, keinginan untuk melakukan akselerasi juga tercermin 7 dari banyaknya bank syariah yang melakukan aksi korporasi. Tak terkecuali bank-bank BUMN, yakni Bank Mandiri Syariah, BNI Syariah, dan bank syariah milik BRI Syariah.

Pada tanggal I Februari 202I, bersamaan dengan Zhu Ma Dasser Achill I442 H ke-I9, tercatat sejarah awal oleh lpenggabungan Bank Syariah Mandiri, BNI Syariah, dan BRI Syariah menjadi satu kesatuan yaitu Bank Syariah Indonesia (BSI). Penggabungan ini menggabungkan keunggulan masing-masing dari ketiga bank syariah untuk memberikan layanan, jangkauan, kuota permodalan yang lebih lengkap. Didukung sinergi dengan induk perusahaan (Mandiri, BNI, BRI) dan komitmen pemerintah melalui Kementerian Badan Usaha Milik Negara, Bank Syariah Indonesia di bangun untuk bersaing secara global. Penggabungan ketiga bank syariah tersebut merupakan upaya mewujudkan Bank Syariah yang menjadi kebanggaan masyarakat, energi baru bagi pembangunan ekonomi bangsa, dan diharapkan dapat memberikan kontribusi bagi kesejahteraan masyarakat luas. Kehadiran Bank Syariah Indonesia juga mencerminkan wajah bank syariah di Indonesia. Ini modern, universal dan menawarkan semua hal yang baik di alam (Rahmatan Lil `Aalamiin). ${ }^{19}$

Oleh karena itu, awal dari Bank Syariah Indonesia cabang Sumberrejo adalah Bank Syariah Mandiri. Didirikan antara Agustus 201 I hingga I 1Februari 202I, akhirnya diganti dengan nama Bank Syariah Indonesia yang berlokasi sebelah utara pasar Sumberrejo, lebih tepatnya J1. Raya Sumberrejo No.3 I0 Bojonegoro (0353) 333475 .

${ }^{19}$ Observasi di Bojonegoro I5 November 202I.

Volume. IO/No. I/Januari 2022 Al-Iqtishod | 123 


\section{Produk Funding Bank Syariah Indonesia KCP Sumberrejo Bojonegoro}

a. Tabungan Easy Mudharabah

Tabungan easy mudharabah merupakan tabungan dalam mata uang rupiah yang penarikan dan setorannya dapat dilakukan setiap saat selama jam operasional kas di kantor bank tersebut atau melalui ATM. Tujuan dari tabungan easy mudharabah ini adalah mewujudkan kemudahan bertransaksi.

b. Tabungan Wadiah

Tabungan wadiah merupakan tabungan dalam mata uang rupiah berdasarkan prinsip wadiah yad dhamanah ${ }^{20}$ yang penarikan dan setorannya dapat dilakukan setiap saat selama jam operasional kas di kantor bank atau melalui ATM. Tujuan dari tabungan wadiah ini adalah menjaga harta nasabah agar tetap murni.

Syarat dalam melakukan pembukaan rekening yaitu KTP dan NPWP. Dengan tarif dan biaya sama dengan tabungan easy mudharabah, hanya saja pada tabungan wadiah tidak dikenakan biaya adminidtrasi atau biaya administrasi gratis.

c. Tabungan Haji Indonesia

Tabungan haji Indonesia merupakan tabungan perencanaan haji dan umroh berlaku untuk seluruh usia berdasarkan prinsip syariah dengan akad wadiah dan mudharabah. Tujuan dari tabungan haji ini adalah untuk mewujudkan niat suci nasabah ke Baitullah.

Syarat dan ketentuan tabungan haji Indonesia yaitu untuk usia $\geq$ I7 tahun ke atas atau sudah menikah, dan memiliki kartu identitas diri KTP dan tau NPWP.Sedangkan syarat dan ketentuan tabungan haji muda

20 muhammad kambali, "PRODUK OPERASIONALISASI BANK SYARI'AH: STUDI PENERAPAN PRINSIP SYARI'AH PADA BANK SYARI'AH MANDIRI (BSM) DAN BANK ISLAM MALASYA BERHARD (BIMB)," Al Iqtishod: Jurnal Pemikiran Dan Penelitian Ekonomi Islam 9, no. 1 (March 30, 2021): 20-35, https://doi.org/10.37812/ALIQTISHOD.V9I1.225. 
Indonesia yaitu perorangan usia $\leq$ I7 tahun dan belum memiliki KTP, dan dengan kartu identitas diri KTP dan atau NPWP orang tua/ wali.

d. Tabungan Berencana

Tabungan berencana merupakan tabungan diperuntukkan bagi segmen perorangan dalam merencankan keuangannya dengan system autodebet dan gratis perlindungan asuransi. Tujuan dari produk ini adalah untuk mewujudkan perencanaan keuangan nasabah.

e. Tabungan Pendidikan

Tabungan ini diperuntukkan bagi segmen perorangan dalam merenakan pendidikan dengan system autodebet dan mendaoat perlindungan asuransi. Tujuan dari produk ini adalah untuk membantu merencanakan pendidikan buah hati sejak dini.

f. Giro Rupiah

Giro rupiah merupakan titipan dana dari pihak ketiga yang dikelola dengan akad wadiah yang penarikannya dapat dilakukan setiap saat dengan menggunakan Debit, Cek, Bilyet Giro, sarana perintah pembayaran lainnya atau dengan pemindahan bukuan untuk menunjang bisnis usaha perorangan maupun non perorangan dalam mata uang rupiah.

g. Deposito Rupiah

Deposito rupiah merupakan investasi berjangka yang dikelola dengan akad mudharabah yang ditujukan bagi nasabah perorangan dan perusahaan dalam mata uang rupiah. Tersedia jangka waktu I bulan, 3 bulan, 6 bulan dan I2 bulan. Dengan syarat dan ketentuan sama dengan syarat giro rupiah. Untuk tarif dan biaya sebagai berikut:

I) Minimum nominal deposito: Rp2.500.000.

2) Biaya break deposito: Rp25.000. 
Strategi Meningkatkan Funding......

3) Biaya penggantian bilyet rusak: RpI0.000. ${ }^{21}$

\section{Strategi Meningkatkan Funding Pada Bank Syariah Indonesia Kcp Sumberrejo Bojonegoro}

Selama masa pandemi, funding Bank Syariah Indonesia Kcp Sumberrejo mengalami penurunan. Hal ini tentu akan berpengaruh pada profitabilitas bank, sehingga perlu dilakukan strategi-strategi untuk meningkatkan funding. ${ }^{22}$ Strategi merupakan penentuan kerangka dari aktivitas bisnis perusahaan dan memberikan pedoman untuk mengkoordinasikan aktivitas sehingga perusahaan dapat menyesuaikan dan mempengaruhi lingkungan yang selalu berubah. ${ }^{23}$ Sedangkan peningkatan funding adalah upaya untuk meningkatkan simpanan yang telah ada untuk mencapai target penghimpunan dana.

Dari penelitian yang telah dilakukan maka diperoleh beberapa strategi yang dilakukan oleh Bank Syariah Indonesia untuk meningkatkan funding mereka selama masa pandemi, diantaranya:

I. Produk

Bank Syariah Indonesia melakukan penawaran-penawaran produk baru kepada nasabah agar nasabah tertarik untuk menyimpan dananya di bank. Hal ini dilakukan bukan hanya pada nasabah baru, namun juga pada nasabah lama. Akan tetapi pada masa penelitian pihak bank tidak menyebutkan produk baru apa saja yang mereka tawarkan.

2. Promosi

Bank Syariah Indonesia Kcp Sumberrejo juga menggunkan komponen bauran pemasaran berupa promosi. Promosi ini dilakukan dengan memberikan souvenir-souvenir kepada nasabah yang baru dan juga kepada nasabah lama.

\footnotetext{
${ }^{21}$ Observasi di Bojonegoro 2 September 202I

22 Qanitah A An Nabila et al., "PENERAPAN STRATEGI MARKETING MIX UPAYA MENINGKATKAN JUMLAH FUNDING PADA BMT MADANI SEPANJANG," Jurnal Ekonomi Syariah Teori Dan Terapan 8, no. 6 (December 5, 2021): 808-20, https://doi.org/10.20473/VOL8ISS20216PP808-820.

${ }^{23}$ Mudrajad Kuncoro, Strategi Bagaimana Meraih Keunggulan Kompetitif, (Jakarta : Erlangga, 2005), 12
} 
Misalnya jika nasabah melakukan penyimpanan dana di atas Rp200.000 maka akan diberikan hadiah atau souvenir agar nasabah tertarik.

3. Iklan

Selain menggunakan kedua strategi produk dan promosi, Bank Syariah Indonesia Kcp Sumberrejo juga melakukan pengiklanan berupa sebar pamphlet dan brosur.

4. Meminimalisir pencairan dana

Maksudnya adalah ketika terdapat nasabah yang ingin melakukan pencairan dana untuk sesuatu yang kurang penting, bank akan menahan atau menundanya terlebih dahulu.

5. Melakukan kunjungan

Pihak Bank Syariah Indonesia Kcp Sumberrejo melakukan kunjungan kepada nasabah dan calon nasabah. Untuk nasabah, mereka akan di pengaruhi dan diajak melakukan penyimpanan dana di banak, kemudian diarahkan untuk datang ke bank. Untuk calon nasabah, mereka akan dibantu melakukan pembukaan rekening dari lokasi mereka sehingga tidak perlu datang ke bank.

\section{Kendala Yang Dialami Bank Syariah Indonesia Kcp Sumberrejo Bojonegoro Dalam Meningkatkan Funding}

Kendala yang pertama, nasabah banyak melakukan penarikan dana selama masa pandemi dikarenakan banyak karyawan yang di phk sehingga beberapa dari mereka memutuskan untuk mendirikan usaha sendiri untuk menghidupi keluarga.

Kendala yang kedua, banyaknya lembaga keuangan syariah yang lokasinya berdekatan dengan Bank Syariah Indonesia Kcp Sumberrejo Bojonegoro yang memberikan produk-produk sejenis sehingga hal ini mengharuskan marketing Bank Syariah Indonesia Kcp Sumberrejo Bojonegoro untuk pandai dan handal dalam mencari nasabah. Namun antara Bank dan Koperasi terdapat perbedaan, yaitu jika Bank, mereka cenderung pada kalangan menengah keatas, sedangkan 
Strategi Meningkatkan Funding......

koperasi biasanya pada kalngan menengah kebawah. Dan jika bank layanan dan fasilitasnya sudah bagus dan sudah memakai ATM sehingga mempermudah transaksi. $^{24}$

\section{Pandangan penulis tentang strategi dan kendala Bank Syariah Indonesia Kcp Sumberrejo Bojonegoro}

Dari strategi yang dilakukan oleh Bank Syariah Indonesia Kcp Sumberrejo Bojonegoro masih perlu untuk memberi inovasi lagi dalam mempromosikan produk-produk yang ada di Bank Syariah Indonesia Kcp Sumberrejo dalam menghadapi kendala-kendala yang masih perlu untuk di minimalisir, seperti halnya banyaknya lembaga keuangan syariah yang lokasinya berdekatan dengan Bank Syariah Indonesia Kcp Sumberrejo Bojonegoro yang memberikan produkproduk sejenis sedangkan tujuan dari perbankan syariah adalah menunjang pelaksaan pembangunan nasional dalam rangka meningkatkan keadilan, kebersamaan, dan pemerataan kesejahteraan rakyat. ${ }^{25}$ Dan Bank Syariah Indonesia Kcp Sumberrejo Bojonegoro seharsnya lebih kreatif lagi dengan memasarkan produk-produk yang ada sehingga tidak kalah dengan lembaga keuangan di sekitar dengan harapan nasabah lebih banyak yang melakukan fundng di bank tersebut.

\section{E. Simpulan}

Berdasarkan hasil penelitian yang dilakukan, bahwa upaya strategi peningkatan funding yang dilakukan oleh Bank Syariah Indonesia Kcp Sumberrejo Bojonegoro cukup efektif menggunakan 2 komponen bauran pemasaran bberupa produk dan promosi, selain itu juga menggunakan strategi iklan, meminimalisir pencairan dana, melakukan kunjungan. Selain itu, Bank Syariah Indonesi Kcp Sumberrejo Bojonegoro juga menambahkan unsur public relation dan internet banking kedalam strategi

\footnotetext{
${ }^{24}$ Muhammad Kambali and Fatur Rahman, "Pengaruh Aplikasi Muzakki Corner Terhadap Minat Mayarakat Berzakat” 10, no. 2 (2021): 175-84, https://doi.org/10.46367/iqtishaduna.v10i2.413.

${ }_{25}$ Andrianto \& M. Anang Firmansyah, Manajemen Bank Syariah_(Surabaya: CV. Penerbit Qiara Media, 2019), 27.
} 
Intan Ayu, Putri Wulandari,

Sutiya Lestari

pemasarannya. Sedangkan strategi yang paling efektif yang digunakan adalah branding dan penyebaran brosur. Adapun permasalahan yang dihadapi oleh Bank Syariah Indonesia Kcp Sumberrejo Bojonegoro dalam promosi produk terdapat di bidang operasional, yaitu banyaknya nasabah yang melakukan penarikan atau pencairan dana, dan persaingan antar lembaga keuangan syariah.

\section{F. Daftar Pustaka}

An Nabila, Qanitah A, Fitri Nur Latifah, M Ruslianor Maika, Kata Kunci, Baitul Maal Wat Tamwil, Bauran Pemasaran, and Penghimpunan Dana. "PENERAPAN STRATEGI MARKETING MIX UPAYA MENINGKATKAN JUMLAH FUNDING PADA BMT MADANI SEPANJANG.” Jurnal Ekonomi Syariah Teori Dan Terapan 8, no. 6 (December 5, 202I): 808-20. https://doi.org/I0.20473/VOL8ISS202I6PP808-820.

Andrianto \& Firmansyah, M. Anang, Manajemen Bank Syariah (Surabaya: CV. Penerbit Qiara Media, 2019).

Anshari, Abdul Ghafur, Perbankan Syariah Di Indonesia (Jogjakarta: UGM Press, 2007).

Antonio, Muhammad Syafi'i, Bank Syariah Dari Teori Ke Praktik (Depok: Gema Insani, 2018).

Data dan statistik dalam https://www.ojk.go.id/ 20 september 2019/ diakses I7 januari 2022.

kambali, muhammad. "PRODUK OPERASIONALISASI BANK SYARI'AH: STUDI PENERAPAN PRINSIP SYARI'AH PADA BANK SYARI'AH MANDIRI (BSM) DAN BANK ISLAM MALASYA BERHARD (BIMB).” Al Iqtishod: Jurnal Pemikiran Dan Penelitian Ekonomi Islam 9, no. I (March 30, 202I): 20-35. https://doi.org/I0.378I2/ALIQTISHOD.V9II.225.

Kambali, Muhammad, and Fatur Rahman. "Pengaruh Aplikasi Muzakki Corner Terhadap Minat Mayarakat Berzakat" IO, no. 2 (202I): I75-84. https://doi.org/I0.46367/iqtishaduna.vIOi2.4I3.

Kbbi. Wawancara, (online) dalam http:kbbi.web.id/wawancara.html/ diakses I9 Desember 202I.

Kertajaya dan Sula, Syariah Marketing (Bandung : Mizan Pustaka, 2006).

Volume. IO/No. I/Januari 2022 Al-Iqtishod | 129 
Strategi Meningkatkan Funding......

Mardiyanto, Eko, Stai Al-Azhar, and Menganti Gresik. "Implementasi Marketing Mix Dalam Pemasaran Perbankan Syariah.” Al Iqtishod: Jurnal Pemikiran Dan Penelitian Ekonomi Islam 9, no. I (March 30, 202I): 93-I03. https://doi.org/I0.378I2/ALIQTISHOD.V9II.227.

Muhayatsyah, Ali, Fakultas Ekonomi, Bisnis Islam, and Iain Lhokseumawe. "PENGARUH KRISIS EKONOMI 2008 DAN FAKTOR FUNDAMENTAL TERHADAP PENYALURAN PEMBIAYAAN BANK SYARIAH DI INDONESIA." Jurnal Ekonomi Syariah, Akuntansi Dan Perbankan (JESKaPe) 4, no. I (July 27, 2020): I25-I24. https://doi.org/I0.52490/JESKAPE.V4II.772.

Muhamma, Manajemen Dana Bank Syariah (Jakarta: Rajagrafindo Persada,20I4).

Muhammad, Audit \& Pengawasan Syariah Pada Bank Syariah (Yogyakarta: UII Press, 2018).

Nurhatati, Fitri \& Rahmaniyah, Ika Saniyati, Koperasi Syariah (Surakarta: PT. Era Intermedia, 2008).

Pandia, Frianto, Manajemen Dana Dan Kesehatan Bank (Jakarta: Rineka Cipta, 20I0).

Rusby, Zulkifli, Manajemen Perbankan Syariah (Pekanbaru: Pusat Kajian Pendidikan Islam FAI UIR, 20I7).

Rahman, Ahmad Taufiqur, Aunur Rofiq, Nanik Wahyuni, and Ridan Muhtadi. "Analisis Partisipasi Masyarakat Nahdlatul Ulama Dalam Meingkatkan Pendapatan Dana (Funding) Lazisnu Kota Sumenep." Ulumuna: Jurnal Studi Keislaman 7, no. 2 (December I2, 202I): 243-60. http://ejournal.kopertais4.or.id/madura/index.php/ulumuna/article/view/5258.

STAI Al-Azhar Menganti Gresik, Sutono. "IMPLIKASI AKAD MUSYARAKAH MUTANAQISAH PERBANKAN SYARI'AH.” Al Iqtishod: Jurnal Pemikiran Dan Penelitian Ekonomi Islam 8, no. 2 (December 28, 2020): I-I9. https://doi.org/I0.378I2/ALIQTISHOD.V8I2.I52.

www.cnbcindonesia.com/II November 202I / diakses I7 januari 2022. 